\title{
Infrastructural Speculations: Tactics for Designing and Interrogating Lifeworlds
}

\author{
Richmond Y. Wong \\ University of California, Berkeley \\ Berkeley, CA, USA \\ richmond@ischool.berkeley.edu
}

\author{
Vera Khovanskaya \\ Cornell University \\ Ithaca, NY, USA \\ vdk9@cornell.edu
}

\author{
Sarah E. Fox \\ Carnegie Mellon University \\ Pittsburgh, PA, USA \\ sarahf@andrew.cmu.edu
}

\author{
Nick Merrill \\ University of California, Berkeley \\ Berkeley, CA, USA \\ ffff@berkeley.edu
}

\author{
Phoebe Sengers \\ Cornell University \\ Ithaca, NY, USA \\ sengers@cs.cornell.edu
}

\begin{abstract}
This paper introduces "infrastructural speculations," an orientation toward speculative design that considers the complex and long-lived relationships of technologies with broader systems, beyond moments of immediate invention and design. As modes of speculation are increasingly used to interrogate questions of broad societal concern, it is pertinent to develop an orientation that foregrounds the "lifeworld" of artifacts - the social, perceptual, and political environment in which they exist. While speculative designs often imply a lifeworld, infrastructural speculations place lifeworlds at the center of design concern, calling attention to the cultural, regulatory, environmental, and repair conditions that enable and surround particular future visions. By articulating connections and affinities between speculative design and infrastructure studies research, we contribute a set of design tactics for producing infrastructural speculations. These tactics help design researchers interrogate the complex and ongoing entanglements among technologies, institutions, practices, and systems of power when gauging the stakes of alternate lifeworlds.
\end{abstract}

\section{Author Keywords}

Speculative design; infrastructure; lifeworld; design research; futures; infrastructure studies

\section{CSS Concepts}

- Human-centered computing HCI design and evaluation methods

\section{INTRODUCTION}

Over the last two decades, the HCI community has taken up modes of speculation such as critical design and design fiction to interrogate emergent technologies. From faraday

\footnotetext{
Permission to make digital or hard copies of all or part of this work for personal or classroom use is granted without fee provided that copies are not made or distributed for profit or commercial advantage and that copies bear this notice and the full citation on the first page. Copyrights for components of this work owned by others than the author(s) must be honored. Abstracting with credit is permitted. To copy otherwise, or republish, to post on servers or to redistribute to lists, requires prior specific permission and/or a fee. Request permissions from Permissions@acm.org.

CHI '20, April 25-30, 2020, Honolulu, HI, USA

(C) 2020 Copyright is held by the owner/author(s). Publication rights licensed to ACM. ACM 978-1-4503-6708-0/20/04 ..\$15.00

https://doi.org/10.1145/3313831.3376515
}

cages [26] to technologies of birth control [76], researchers develop conceptual artifacts and experiences to evoke alternative sociotechnical worlds - exploring the possibility of different social values, norms, behaviors, and material configurations. These arguments often center imagined technological products and their immediate worlds of use, or the ways in which a potential consumer or user might take up the artifact in their everyday life. Designers Dunne and Raby, for example, present a series of protective devices meant to guard a user from harmful electromagnetic waves emanating from household appliances [26]. Brown et al. reimagine the familiar IKEA Catalogue [13], promotional material from the large multi-national furniture corporation. Through seemingly ordinary images and product descriptions, the designers' speculative intervention reveals itself as broad datafication of generic domestic environments familiar to many readers.

Such speculative design strategies produce evocative scenarios for thinking through the ramifications of direct use. With the IKEA Catalogue, for example, the viewer might easily ponder the implications of sleeping in a data-enabled bed. However, other types of questions remain more implicit: for example, questions about the labor it might take to create the bed, the practices that might arise from long-term use of that bed, or the regulatory frameworks that may emerge around the data derived from that environment.

In this paper, we ask how speculative design can be used to explicitly center and raise questions about the infrastructures within which products are entangled. We contribute eight specific tactics to expand design researchers' purview, and enable the $\mathrm{HCI}$ and design communities to more readily consider the complex and longlived dependencies of technologies within broader systems, such as the regulatory worlds in which potential technologies might live, the environmental impacts of their development and data storage, the (re)appropriation and long-term use of imagined devices, and the maintenance and repair labor required to sustain designs over time. 
To begin to understand the material structures, politics, and practices of worlds that do not yet exist, we turn to scholarship within and just outside of the HCI community on infrastructure studies. This body of social science research focuses attention beyond moments of invention and design to attend to the ongoing social and systemic mechanisms necessary to a technology's existence over time. Using techniques of archival study, ethnographic observation, and discourse analysis, scholars draw out questions around the politics and practices required to build and support design: What practices, norms, and values allow for or an artifact or system to exist in the world? What forms of social and technical organization are required to sustain it? In employing this work, we seek to integrate infrastructural perspectives into speculative practices, allowing design researchers to more explicitly foreground the cultural, regulatory, environmental, and repair conditions that might enable and surround particular future visions. In doing so, we present the notion of infrastructural speculation, a lens to center and unravel the lifeworlds of speculative designs. We argue a move to consider the infrastructural is crucial as modes of speculation are increasingly used to interrogate questions of broad societal concern such as environmental degradation and climate change, the role of big tech in campaigns of political radicalization, and widening income inequality across the world.

We begin this paper by charting speculative practices within and around the HCI community. We then outline science and technology studies (STS) and communication scholarship on infrastructure studies, and ways in which such work is in dialogue with repair and maintenance movements within HCI. Building from this discussion, we reflect on our own practice and a broader body of design research to retrace where infrastructures might be present, explicitly or implicitly, within existing speculative design projects. We take up the phenomenological concept of "lifeworlds" to examine the social, perceptual, and political environment in which a designer places an imagined artifact. Through our reading of speculative design through the lens of infrastructure studies, we contribute a set of eight tactics meant to support HCI researchers seeking to craft speculative design proposals. We discuss how these tactics can help HCI researchers further interrogate the messiness and contingency of future sociotechnical lifeworlds that surround their speculative artifacts, and how these visions can be enriched by engaging with such complexities.

\section{RELATED WORK}

Before we outline our use of the concept of lifeworlds and present a series of tactics meant to bring attention to the sociotechnical context surrounding speculative artifacts, we first describe bodies of work within and just outside of the HCI community that animate our discussion.

\section{Speculative Design Practices}

Critically oriented speculative practices use the process of design to surface values, critique social issues, and present alternative visions of the future by creating conceptual proposals and artifacts [48]. These include practices such as critical design [2,26,73], speculative design [1,27,35,104], adversarial design [22], and design fiction [5,7,52,56]. Each of these research approaches creates objects, representations, or depictions of possible or alternate futures, often removed from immediate practical concerns of implementation and commercial viability [104]. Instead they utilize what Dunne terms "para-functionality" [25], or the use of normative design conventions to give the appearance of a product, while also seeming out of place, unusual, or unfamiliarallowing for "what was invisible and lost in the familiarity of the everyday" to be "made visible" [59]. Producing parafunctionality when crafting an artifact allows both the designer and viewer to reflect on social and political questions posed by the designs.

Efforts to cast the familiar into question run through much speculative work within HCI. Lindley et al., for example, describe speculative practices as creating "plausible, mundane, and speculative futures" [54:272], interacting with the broader social and political world surrounding the artifact. Similarly, Dunne and Raby describe "values fictions," or the use of plausible technologies to depict alternate sets of social values (as opposed to science fiction which explores alternate technologies within a similar social milieu) [26:63]. Coulton et al.'s discussion of design fiction as a "world building" activity also begins to shift analytical focus away from individual speculative artifacts and towards the broader world in which they exist [18].

Importantly, Lindley et al. suggest that technologies can be "meaningfully 'analogued' for the proximate future" and analyzed through sociological lenses, listing social constructivism as one possible approach [54:272]. This leads us to consider lenses useful in interrogating the "analogued" worlds depicted through speculation. We build on prior researchers' insight of identifying infrastructures as sites for speculation, futuring, and fiction in order to think about worlds beyond individual artifacts (e.g., $[77,86])$. We look specifically to analytical lenses from infrastructure studies to inform our speculative practices. We consider what infrastructure studies might contribute to ongoing debates and critiques of speculative design.

\section{Critiques of Speculative Design}

While a potentially useful set of design and research practices, speculative design has been critiqued for often coming from a privileged perspective, leading to several marked shortcomings and oversights. Tonkinwise points to a lack of discussion of race or class, an overly US and European focus, and an overt capitalistic aesthetic of fictional "products" [95]. Similarly, designers Oliviera and Prado argue for speculative and critical design practices that better represent multiplicity and identify the ways in which differences and power discrepancies appear [66,98]. Additional critical scholars call for greater recognition of local design practices, rather than assuming that only 
particular technologies (from the global north) are legitimate forms of design [28]. Søndergaard and Hansen, drawing on Haraway, call for design futuring practices to "stay with the trouble," to think beyond privileged individual needs and consumption-based experiences [88].

In the following sections, we look to perspectives from infrastructure studies and offer the concept of lifeworlds as one step toward addressing some of these critiques. These lenses help foreground ongoing political- and power-laden practices required to promote and maintain technologies, and highlight how macro-level systems can be experienced in multiple and unequal ways at the micro-level. We use these lenses to extend existing design practices into design tactics for "infrastructural speculation." This work builds on scholarship that seeks to create tools that make critiques of design futuring more actionable - such as checklists for noncolonialist speculative design [68], methods cards, and analytic games [30] - and seeks to surface more critical discussion around the politics of creating futures $[60,80]$.

\section{Infrastructures Studies}

Infrastructures are built on a combination of specific technologies, are enabled by social institutions through activities such as standards-setting, maintenance, and repair, and support particular forms of human actions while complicating others $[9,44,89]$. For example, the electrical grid is built using technologies such as electrical substations, dams, and power plants. It relies on social institutions such as power companies and regulatory agencies that shape and maintain it. Yet, access to, and experience of electrical power is variable. In other words, infrastructure is always already sociotechnical: it includes technological components as well as the social institutions and practices that make it durable, and it scaffolds further social practices.

Analytical lenses developed in science and technology studies (STS) focus on the institutions and practices that form and maintain infrastructures, which may at first be hidden from view $[8,89]$. Bowker et al. write that this focus involves "shifting the emphasis from changes in infrastructural components to changes in infrastructural relations. Infrastructure is indeed a fundamentally relational concept; it emerges for people in practice, connected to activities and structures" [9:99]. HCI, information studies, and $\mathrm{CSCW}$ scholarship concerned with infrastructures focuses on the study of computing and information systems beyond immediate moments of design or use (e.g., $[33,40,43,45,55,78,92,103])$. Maintenance and repair labor, technology policy, and political and economic conditions, for instance, all move forward as objects of analysis in such studies. Infrastructural viewpoints, in turn, help us as design scholars to consider how technologies inhabit a lifetime of relationships in real, complex social worlds. As Jackson et al. describe, while infrastructures are emergent (even when planned, new properties emerge as the system develops), initial choices in their design matter and can reverberate long after those decisions were made [44].
Rather than wait for infrastructures to breakdown to see or understand them, we can look down at our feet to the manholes that expose the underwater sea cables that deliver the world's internet $[69,90]$, and back to the forgotten stories of companies that have failed [24] or to outmoded forms of technology production $[47,79,81,85]$. By bringing lenses from infrastructure studies together with speculative design practices, we build on Steinhardt and Jackson's call to "more squarely integrate futures - and the work we do to imagine, contest, and produce them-into our studies of sociotechnical systems." [93:443] We reflect on the idea that speculative design is concerned with infrastructures and infrastructuring, but these concerns are often not explicitly discussed or analyzed. Bringing new lenses to existing speculative work can help designers and researchers more explicitly do the work of thinking through infrastructural issues and questions. To begin to do this work, we draw on the phenomenological concept of "lifeworlds" to examine often implicit aspects of speculative design.

\section{LIFEWORLDS}

Recognizing the dual nature of producing speculative design with an infrastructural sensibility, we consider the work of designing an artifact, as well as the work of designing an imagined world in which that artifact would fit. This move draws on the phenomenological concept of 'lifeworld' (German: Lebenswelt), originally defined by German philosopher Edmund Husserl as the realm of what is selfevidently given through experience $[41,82]$. Philosopher and sociologist Jürgen Habermas refers to "life-world" as the normative social context in which "unmediated certainty of tacit and unquestioned knowledge is predominant" [74:540fn]. Social scientists and anthropologists draw on this concept to describe social realities, e.g. "stable institutions, rituals, and beliefs that take on a life of their own, and become effectively 'objective' for the agents who take them for granted as facts of life" [4,58:22]. Within HCI, the concept of a lifeworld has been drawn on to delineate the seemingly mundane interaction paradigms of the "workaday world" $[62,83]$ and to describe the how the presence of an object affects the material and perceptual experiences of a potential user [38]. In both cases, the lifeworlds are taken as real, operating in the world as experienced by users.

Our own use of lifeworlds is grounded in an understanding that every design projects lifeworlds - intentionally or not. Bearing some similarities to Kirby's discussion of worldbuilding and the suspension of disbelief in design fiction [49] and the concept of worldmaking in futures studies [37,97], these lifeworlds are characterized by the things that must be true, common-sense and taken-for-granted in order for the design to work. For example, a Fitbit watch could be said to inhabit a lifeworld in which users care about their fitness, do not trust their personal experience to be adequate to drive fitness efforts, and value quantified representations as markers of an outside truth about themselves. 
In the work of speculative design, we consider how the lifeworlds of the future are projected through an imagined design. A projected lifeworld can be thought of as the lifeworld one would have to inhabit in order for the design to make sense. Such designs might project strange or disarming lifeworlds in order to destabilize and question the reality we live in, showing alternatives that are almost — but not quitereal. By asking what kind of world a design might design fit into and what the world holds to be true (i.e. how is it like, or unlike, our world?), we are able to analyze the expectations that are built into a design.

We find that projected lifeworlds are already implicit in existing speculative design work, but attention is often drawn most immediately to the speculative design artifact. Some designs may imply infrastructural qualities in the background of the lifeworld that it creates and inhabits. Other designs that might not identify as "speculative" may address infrastructural questions of future visions. For example, Wong and Mulligan use infrastructural perspectives to examine Google Glass' and Microsoft Hololens' vision videos, and the implicit privacy laws and norms necessary to make these future, corporate lifeworlds possible [105].

The design tactics presented in this paper are intended to help design researchers use speculative design to explicitly ask questions or articulate arguments using the lenses and concepts of infrastructure studies. By recognizing how infrastructures already exist in the backgrounds of speculative designs, these tactics help design researchers redirect attention more explicitly to the "background" practices surrounding technologies beyond use, to think about the broad - yet differential - impacts of infrastructures and contend with questions of institutional power.

\section{TACTICS FOR INFRASTRUCTURAL SPECULATION}

In this section, we build on what we see as a productive overlap between infrastructural lenses and speculative techniques to describe eight tactics for developing and analyzing the imagined lifewords of a design. Each of the authors' work sits at the intersections of HCI, design, and STS, and each takes up techniques of speculation to engage in broad discussions about the worlds various stakeholders want to see or avoid, as well as to enrich our own reflective analysis. It is out of our ongoing commitment to these modes of thinking and practice that we developed the research at hand. In presenting these tactics, we draw from an analysis that involved a literature review of scholarship on infrastructures studies, alongside re-readings of our own design work and others' speculative projects for infrastructural elements that might explicitly or implicitly exist within them. We wrote reflective memos that included a summary of an important concept or insight from infrastructure studies, proposals of how a speculative designer could make use of that concept, and examples of existing design projects that seemed to touch on that concept, even if implicitly. During bi-weekly meetings, we reviewed the memos, iteratively refined our interpretations over time (sometimes merging and splitting insights), and developed a set of "infrastructural insights" and associated "design tactics" that arose out of themes such as assemblages, seams, and expanded notions of human-object relations.

These tactics aim to help designers consciously and purposefully place and reflect on the role of infrastructures in their speculative work. We aim to draw out and extend design tactics from prior work in ways that make it easier for designers and researchers to do speculative work while explicitly considering infrastructural insights. Each tactic discussion is grounded in a particular insight from infrastructure studies, describes how that infrastructural insight has affinities with speculative design research and existing design practices, illustrates the tactic through exemplars, and highlights the types of infrastructural interrogations that the tactic helps open up.

\section{Insight: "Infrastructural inversion" shifts emphasis from individual artifacts to assemblages of artifacts, people, practices, and social institutions}

Bowker and Star's concept of "infrastructural inversion" is an analytical move to foreground relationships among people, practices, artifacts, and structures that normally exist in the background of a situation or activity $[8,10]$. This form of analysis shifts attention away from an individual design artifact to how that artifact relates with complex worlds of use. In a similar fashion, speculative design uses the development of an object or device to articulate questions about the relationships among people, practices, artifacts, and structures that exist in the lifeworld. Speculative designs can be crafted in ways to emphasize the importance of the (background) lifeworld as being just as, if not more, important than the speculative artifact itself.

\section{Design Tactic: Place the same speculative artifact in multiple} lifeworlds.

In deploying this tactic, the design researcher takes a single artifact and articulates multiple lifeworlds in which that artifact might make sense. This tactic de-centers the artifact as the main unit of analysis, and instead looks to the assemblage that constitutes the artifact and its lifeworld. For example, Pierce's smart product collages re-deploy existing consumer IoT cameras in ways that suggest alternative lifeworlds, beyond what is depicted in advertising and marketing materials [70]. Pierce uses metaphors of lamps and curtains to speculate lifeworlds where IoT cameras have physical on/off switches, curtain shades and covers attached to them, or used like interior lamps for decorative and moodsetting purposes. One can look at these re-deployments to ask what other lifeworlds might make sense for the IoT camera. Perhaps a lifeworld where IoT cameras are used decoratively and aesthetically like lighting today? Or a lifeworld in which a marketplace provides IoT camera add-ons that subvert surveillance, such as physical lenses, covers, switches, and jammers? Or one where people adopt, but mistrust their home IoT devices? 
By explicitly portraying multiple alternative lifeworlds, design researchers can begin to interrogate the coconstruction of artifact and its world. The diversity of lifeworlds depicted through this tactic also sheds light on the multiplicity of the present reality. Within the lifeworld that we inhabit, technologies exist in an array of sociotechnical assemblages and are interacted with in a variety of ways. It also shifts the lens of inquiry away from the artifact itself, focusing instead on the importance of the lifeworld surrounding the "background" of the artifact. This reflection of multiplicity within a single lifeworld leads to our second infrastructural insight.

Insight: Infrastructures are widely shared, but are experienced differently

Infrastructures occur simultaneously at global levels and within specific local contexts - or, in the words of Star and Ruhleder, "when local practices are afforded by a largerscale technology" [89:114]. Scholars of feminist theory, Latin American political philosophy, and related critical scholarship argue for recognizing, engaging with, and designing for the situated multiplicities that exist within such lived worlds. Some call for greater recognition of local practices, particularly those not from the global north, as legitimate forms of design [28]. Others argue for speculative and critical design practices that represent multiplicities and identify the ways in which differences and power discrepancies manifest and compound [66,98].

Speculative design calls on the viewer to assume the perspective of a user, but it is often a single 'strange' userone who lives in a different lifeworld than the viewer, and thus exists in a world with different values, norms, or practices. This orientation inherently involves recognizing a difference of perspective, between a reader and a 'user' in the lifeworld, but speculative design could also consider multitudes of user perspectives within the lifeworld.

Design Tactic: Show a single artifact from multiple (user) perspectives within the same lifeworld.

Within a single projected lifeworld, there are many different local situated practices of use. This tactic asks design researchers to articulate how multiple kinds of users would orient to an artifact. As an example, we look to Wong et al.'s speculative design workbook of sensing technologies inspired by the science fiction novel The Circle [106]. Part of the workbook depicts the same miniaturized mobile camera artifact in relation to multiple users within the same lifeworld (that which was presented in the novel from which the technology is derived). The same camera technology is simultaneously marketed to and adopted by sports enthusiasts, policing organizations, animal rights organizations, and libertarian property rights advocates. But the analytical issues and questions raised differ based on where in the lifeworld it is situated. For instance, the policemarketed version of the camera gives the state the power of surveillance, while the libertarian property rights version of the camera gives the power of surveillance to people who view state power as a threat. Considering that these exist in the same lifeworld also means having to contend with the tensions and seemingly contradictory uses, which also arise with real world products.

In another example, Desjardin et al.'s Bespoke Booklets offer a set of speculative design sketches exploring domestic IoT futures [19]. Each of the eight booklets were designed specifically for (and with) eight dwellers of a diverse set of home environments. Each booklet's speculative designs imagine possibilities for living with devices and data based on the researchers' and dwellers' understandings of that particular space. Rooted in a feminist perspective [32], this project aims to move beyond dominant use cases of home IoT to instead recognize a multiplicity of uses that may occur within specific situated environments.

With this tactic, design researchers can explicitly ask or craft arguments around the question raised by infrastructure scholars Bowker et al.: "How are an infrastructure's qualities being distributed between the local and the global?" [9:102]. This tactic can help a researcher understand aspects of systems that are shared broadly, while at the same time recognizing how local experiences may differ or even present contradictory uses. Placing a single artifact in multiple places of use in the same lifeworld highlights multiple co-occurring relationships surrounding the artifact, drawing attention to the situated contexts of use. This highlights how that the social meaning of artifacts is coconstructed between the (more global) artifact and the (more local) multiple relationships it has to its lifeworld.

Insight: Infrastructures highlight that people have a broad range of relationships to technological systems Infrastructure studies scholars often focus on the practices required to support sociotechnical systems, recognizing a broader set of stakeholders, such as those who repair and maintain systems (e.g., work of Wikipedia editors [36,50]), or those who do work to re-design, manage, sell, regulate, hack, or dismantle systems. This insight then, looks at uses beyond use, to identify how artifacts have different types of relationships with humans beyond the end user's use of the artifact. This connects with strands of existing HCI design practices. Sustainable HCI research, for example, considers a broader set of relations among technologies, supply chains, channels of distribution, recycling, and labor [6]. Value sensitive design's focus on both direct and indirect stakeholders [34] and studies of managers, repairers, and hackers $[33,40,93,99]$ help HCI consider the expansive ways humans interact with and relate to technical systems.

While most speculative design artifacts foreground how users might interact with an artifact, speculative lifeworlds implicitly suggest that there are relationships and stakeholders beyond end use. For example, Odom et al.'s speculative design proposals for diverse homes are presented as user reviews, ads, app store entries, and Amazon.com product pages [67]. These position the reader as a potential user or consumer of these products and services. However, a viewer with an infrastructural mindset might find that the 
catalog implicitly suggests a range of additional relationships beyond users' use. What does it mean that products for seemingly non-mainstream forms of housing are sold on mainstream sites? How might these products interact with regulatory definitions of the "household"? How might the data collected from these products be re-appropriated by other dwellers, technology developers, or other stakeholders? An infrastructural speculative design approach allows designers to ask such questions more readily.

Design Tactic: Focus lifeworld descriptions on stakeholders beyond users, and relationships beyond use.

For instance, Nathan et al.'s value scenarios bring together elements of value sensitive design and critical design to explicitly imagine scenarios that highlight multiple types of stakeholders and their relationships with a technical system over longer periods of time $[63,64]$. One value scenario depicts a speculative system SafetyNet, a system that tracks publicly available demographic and criminal data to create maps that alert urban travelers when they are going into "potentially unpleasant or dangerous" areas [63]. The scenario describes a moment eight years after the introduction of the system, noting its effects on a non-user who lives in a neighborhood SafetyNet marked as poor, as well as a street gang who has re-appropriated the tool for their own use as a profiling tool. Both of these occur in a city that is more broadly segregated into homogenous enclaves due to the system's adoption. This scenario foregrounds relationships of non-use and re-appropriation (rather than use). It also invites additional speculation about the lifeworld, such as how might city officials seek to regulate, maintain, or disrupt the system?

Stead's Toaster for Life presents a networked toaster with sustainable attributes, including the ability to repair, upgrade, customize, recycle, and track component parts [91]. The fiction foregrounds a set of relationships and practices with the toaster that go beyond use. The prototype, for example, is modular and made without screws or hidden seals, centering repair and maintenance practices as a key mode of interacting with the toaster. The fiction also points to a set of broader stakeholders who might interact with the toaster through practices of recycling, fabrication and customization, and tracking of the toaster's components throughout its lifecycle.

While the previous infrastructural insight and design tactic focused on a diversity of users, this tactic focuses on the diversity of relationships people might have, directly or indirectly, with technical artifacts. For instance, how might a data privacy regulator act differently in the United States versus the European Union? What forms of work or types of social and technical infrastructures might be necessary to maintain a system across time? Who does this work, and how is it valued (or not)? How might these relationships, social norms, and practices change over time? What alternative, and potentially adversarial, relationships might people have with a speculative artifact? This tactic can be used to explore such questions around the multifaceted relationships and practices related to speculative artifacts.

Insight: Technologies are not deployed by themselves, but into an existing ecology of sociotechnical systems

Infrastructures studies acknowledges that technical artifacts do not exist by themselves, but rather exist in a broader ecology of sociotechnical systems that affect their creation and ongoing use. This ecology might include interoperability standards, laws, marketplaces, rules set by platforms, communities of practice, and other technical systems that allow the artifact to function and shape its political meaning. Some speculative design practices have begun to depict an ecology of related artifacts within one lifeworld, to aide in the suspension of disbelief. These strategies build on Kirby's concept of diegetic prototypes, or technologies that function in the background of a film [49]. Coulton et al.'s concept of design fiction "world building" suggests creating a range of artifacts within the same lifeworld that can serve as multiple "entry points" for the viewer [18].

With an infrastructural lens, a set of co-existing artifacts can also do analytical work, acknowledging that a single lifeworld hosts multiple kinds of people, social structures, institutions, and infrastructures. Ecologies construct not just secondary artifacts, but also the interstitial space between them, understanding how these artifacts fit together to create a whole.

Design Tactic: Create multiple artifacts that live in a single world, leaving out the "central" artifact to which they orient.

This tactic helps a design researcher explore the broader sets of sociotechnical systems upon which a "central" artifact of study might rely. One strategy for enacting this tactic is to depict artifacts surrounding a central artifact of study, while never depicting the central artifact itself. For instance, Wong et al.'s When BCIs have APIs design fiction speculates how a brain computer interface (BCI) device could be used in perpetuating the power dynamics that exist in crowd work [107]. The authors do not directly depict the brain computer interface device itself. Instead, an ecology of speculative artifacts surround a particular use of the brain computer interface in crowd work: an API underlying the BCI software, a StackOverflow.com post where a developer is trying to use the API, a memo by the company using crowd workers, and a forum by crowd workers who use the BCI.

Another example is Lindley et al.'s Game of Drones design fiction, which depicts a world where drones are used to provide public services in a UK city [53]. The speculative world is crafted by presenting legislation allowing for this particular deployment of drones; a drone enforcement system which includes public docking and recharging stations; a gamification system for pilots and users; and drone activity notification signs. While the drones are the central artifact of study, the design artifacts depict other parts of the ecology within which the drones would be deployed.

While similar to Briggs et al.'s strategy of invisible design [11], rather than focusing on the "central" artifact's 
ambiguity, this tactic helps the design researcher re-focus their attention to a broader network of related artifacts and practices. What other artifacts or practices are necessary for the end user interaction to exist? What artifacts might be necessary to help maintain and repair the end user interaction (e.g., updating, adapting, or repurposing an API)? How are conventions of practice set and normalized (e.g., training manuals, laws and regulations)? Depicting an ecology of artifacts in same lifeworld destabilizes the centrality of the interaction between the end-user and user interface, focusing instead on sites of interaction beyond, but implicated by, a central artifact.

Insight: Historical sociotechnical imaginaries are enrolled in constructing infrastructures, which require the deployment of many actors and resources

STS scholar Sheila Jasanoff characterizes sociotechnical imaginaries as "collectively held, institutionally stabilized, and publicly performed visions of desirable futures, animated by shared understandings of forms of social life and social order attainable through, and supportive of, advances in science and technology" [46:4]. While sociotechnical imaginaries are future-oriented, researchers also look to historical imaginaries to understand the social values that informed the design of and practices related to past technologies.

Such work also illuminates how past imaginaries touch present-day infrastructures and technologies. Consider the Picturephone, a video telephone technology developed by AT\&T in the 1960s. While a commercial failure, the Picturephone established a sociotechnical imaginary of a mediated future that drove future technological development: "It transformed technological rhetoric into design and technological enthusiasm into practice. [...] It motivated construction of a new communications architecture and promoted a new vision of information as the manipulation of voice, image, text, data, and, yes, even video through a single network" [57:78]. The sociotechnical imaginary of video telephony established in the 1960s influenced the development and construction of internet and media infrastructures that persist in the present.

Similarly, speculative design aims to shape people's visions of possible futures and mobilize affect in order to construct alternative futures imagined by the designers. Speculative design can thus contest, create, and enact sociotechnical imaginaries [96]. Just as sociotechnical imaginaries can be used to look both to the future and the past, we can similarly use speculative design to re-orient toward the past.

Design Tactic: Use past aesthetics, practices, technologies, in speculations about alternate presents or about the future.

This tactic asks designers to create speculations using technologies or aesthetics from the past. This serves to prompt questions about why we consider certain technologies "new" or "old," and helps surface connections between current technologies and historical systems and practices. In an example of this tactic at work, Tanenbaum et al. argue that communities engaging in DIY steampunk practices create speculative design fictions that use aesthetics, materials, and techniques of making to explore "alternate models of values and meanings" [94].

One way to enact this tactic is to create speculative designs using practices and technologies of the past. Rosner, Shorey, and colleagues facilitate "making core memory" workshops to "re-presence" the gendered labor of weaving core memory, crucial to powering the 1960s Apollo space missions $[79,85]$. They use this embodied technique to open "an indeterminate past to illuminate the networks of labor called into being by technological artifacts." [85]. Jungnickel similarly describes taking up sewing as a design method to recreate and perform in women's Victorian-era cycling costumes, gaining insight into how women were expected to move through public spaces at the time and the forms of resistance that women embedded into the act of developing patented garments [47]. While these researchers distinguish these projects from speculative design, these acts of represencing through material engagement could be extended into the creation of speculative designs. By incorporating historical practices and technologies into visions of broader temporal contexts, design researchers can begin to illuminate continuities and disconnects between our visions of past, present, and future.

Design Tactic: Design past (or failed) technologies from the perspective of the future.

This tactic asks designers to position themselves in an imagined future, and to consider what past or failed technologies look like from that perspective. In part, this is inspired by vaporware - technologies that were announced, but never widely produced or released $[51,105]$. How might technologies and practices that seem novel in the present be viewed as old, unexciting, or unsuccessful in the future?

In one example of this tactic, Dew and Ribes ask students in their course on Human Centered Design to create "technofossils" by analyzing and unpacking a technology that exists in the present day from the perspective of an archaeologist reporting from a field site in the year 3000 $[20,21]$. This archaeological perspective draws attention to questions such as, "what does the artifact tell us about the culture from which it came?"; "how did it get used?"; and "what traces of the technology (or associated objects in its ecology) persist over time?" Mitman et al.'s edited book Future Remains conducts a similar exercise through objects ranging from pieces of concrete to a Blackberry phone. Framed as remains of humanity, the authors explore how these objects provide insight into how human practices are intertwined with economic, social, and environmental forces [61]. These exercises provide insight into how current relations among humans and objects might persist and change over time. Furthermore, considering unbuilt or unfinished infrastructures can provide insights involving the temporalities of infrastructures, such as understanding the futures suggested by unfinished projects, alternative futures 
deployed by forces keeping projects in unfinished states, and how unfinished projects can nevertheless still "reshape social and political life" [16:17].

Together, these historical tactics help design researchers foreground several lines of inquiry through speculative design. First, they help interrogate how sociotechnical imaginaries construct visions of the future (or the past) and enroll broader practices and values in maintaining those imaginaries. Sociotechnical imaginaries surrounding infrastructures can portray people as being "in the future" or "in the past," but this tactic allows design researchers to complicate these formulations. Second, these tactics surface the temporal contingencies and long-lasting nature of infrastructures. Technologies in the present have historical lineages and will help propagate similar lineages into the future. Third, these tactics open up history to forms of speculation. Historical technological developments and practices may seem natural or obvious, but bringing past technologies and practices into the present helps open up their politics in new ways.

Insight: Mundane organizational work underlies much of ongoing technology maintenance and use; Violence can be (un)intentionally inflicted through this work

New technologies are deployed in relation to existing institutions and systems of power. These systems of power are configured in ways that help some people and harm others. These harms often do not come from an "evil mastermind," but are rather perpetuated through pervasive, ongoing bureaucratic work. Any individual task or decision on its own may not seem powerful, but at scale has the ability to help and harm large groups of people.

For example, Eubanks discusses how U.S. state governments' adoption of seemingly neutral automated systems to determine eligibility for public assistance benefits become intertwined with regulatory forms of power to create systems of surveillance on the poor. Eubanks points to infrastructural qualities of these systems, describing their sociotechnical complexity and persistence: "New technologies develop momentum as they are integrated into institutions. As they mature, they can become increasingly difficult to challenge, redirect, or uproot" [29:184-187]. In a recent case, an algorithm used by the U.S. government to detect retailer fraud involving nutritional assistance program funds misclassified a small storeowner's local IOU practices and disqualified the storeowner from the government program [14]. A collection of seemingly small decisions about implementing automated eligibility technologies become entangled in a larger ecology of infrastructures that create harms and micro-dystopias in the everyday lives of poor and working-class Americans.

Techniques of speculation can be used to look at the everyday and mundane aspects of institutional and organizational power. What are the seemingly quotidian practices of people embedded in organizations and institutions that are responsible for creating, deploying, or maintaining technical systems? What are the broader (intentional or unintentional) effects of those actions, particularly if they lead to harmful outcomes?

Design Tactic: Create mundane artifacts or organizations whose disturbing effects are due to the systems of power and institutions within which they are embedded.

This tactic contrasts with speculative exercises designing intentionally "evil" technologies (e.g., [87]). Rather than the "evilness" of a technology coming from malicious intent of its designers, the "evilness" arises from the systems of power in which the technology is embedded or adopted. Wong's organizational fiction, for instance, depicts UX designers who attempt to surface and address problematic social values related to an harmful use of their platform, but are stymied by their company management's desire to not lose a contract with a particular client; they are later are replaced by contractors or "ethics strikebreakers" who do the problematic work instead [102]. This fiction highlights a moment of values contestation that may not be apparent when looking at a system from an end user's perspective: engineers and designers speak out against a problematic use of their product, but their concerns get dismissed and obfuscated by management. The negative outcomes from this scenario do not arise from some evil intent of engineers or designers nor a problematic technical system, but rather from the organization's arrangement of power and the encompassing industrial structures of financial reward.

This tactic calls attention to systems of power and inequality of the past and present, and calls on us, as design researchers, to grapple with how those systems might persist in the futures we imagine. Notably, this tactic is not about creating grand futuristic dystopias. Instead, it seeks to recognize the current and past dystopias that people face in their everyday lives, surface the systems of power that (re)create those dystopias, and imagine how those assemblages might be (re)configured in the future. Speculative futures that focus on relations of power surface how institutions and power structures that exist today (often in the background) can be (re)configured in ways that still exert power in the speculative future. This tactic examines how infrastructures enable or constrain action in ways that can at first seem subtle, but cause enduring, large-scale effects.

The design researcher might use this tactic to interrogate the bureaucratic surround of the artifact, the forms of labor and institutional organization are required for the artifact to be used or deployed, and how power is implicated. These questions provide insight into how technologies produce shared effects outside of individual choice-how, through forms of institutional power, technologies can constrain or shape action in uneven ways.

Insight: In contrast to visions of futures where technologies act "seamlessly," we can pay attention to the seams that exist

In conversation with "seamless" visions of ubiquitous technology [100], scholars have discussed how designers 
might focus on the "seams" of infrastructures [17,23,42]. Rather than envisioning a world in which technologies' operations are hidden away, a seamful lens draws attention to its limits (in functionality, interoperability, or infrastructural reach), asking users and other stakeholders to engage with systems at these points of visibility and asking developers to recognize them as opportunities for design. $[12,17]$. For example, Chalmers recognizes that WiFi network coverage is not constant and ubiquitous, and suggests ways that seams can be incorporated as a useful feature, rather than as a problem to overcome [17].

Speculative design similarly engages in the tension between depicting seamless and seamful futures. While corporatebased speculation generally depicts perfect worlds where products are used seamlessly [31,51], speculative design often explores complexities of everyday life, including when technologies fail, break, or need to be used in tenuous or improvised ways [31,65,71]. Pierce and Paulos' concept of counterfunctional design-identifying common positive features of a certain technology and then designing around the absence or restriction of these features [72] - provides one way to think about seams. A more explicit focus on seamfulness can help designers center these complexities and their surrounding practices in imagined futures.

Design Tactic: Incorporate the artful work required to make use of technologies, and design artifacts to foster artful bridging work.

In encountering technological seams, users and other stakeholders practice artful work of (re)design and (re)appropriation in order to make systems work in ways that are useful or beneficial. Extending this into speculative design, speculative artifacts can be designed in ways that not only surface seams, but also ask what appropriation work stakeholders might undertake in bridging seams.

Bennett et al.'s "biographical prototypes" surface stories of people with disabilities and their everyday adaptation of technologies and tools, rather than the typical heroic tales of designer-led accessible design [3]. These material prototypes - such as a spatula wrapped in double sided tape to extend one's reach to gather fallen beads on the floortell stories of the artful (and sometimes disempowering, arduous, or exhaustive) physical, mental, and emotional work that people with disabilities practice in order to bridge the seams that they encounter in "making something work" [3:37]. Bennett et al. describe the stories encapsulated in these prototypes as both reflecting pasts and imagining futures; future design researchers may consider using this technique to create speculative designs that center the work required to stitch seams in everyday experiences.

This tactic draws attention to ongoing forms of re-design and re-appropriation, repair and maintenance, and the conventions and practices that surround technical artifacts. It provides a means to think about futures between completely working and completely broken. Design researchers can use this tactic to ask, what social and technical infrastructures are required for this artifact to work? What practices and norms might people have to do to bridge the seams between the design artifact and other technological and social systems that exist in this lifeworld? Who does that bridging work? What mental and emotional labor is required to bridge seams? How might artifacts be designed to foster particular bridging practices?

\section{DISCUSSION}

An infrastructural speculation is an orientation towards speculation that aims to interrogate and ask questions about the broader lifeworld within which speculative artifacts sit, placing the lifeworld (rather than an individual artifact) at the center of a designer's concern. The tactics in this paper are not exhaustive. Rather, we offer them to as a tool for researchers interested in cultivating infrastructural sensibilities through their speculative work. Taking up these tactics can result in many forms of design and modes of output - ranging from examining pieces of infrastructure, to depicting practices such as maintenance and repair, to creating new forms of experiential or interactive speculations. As with other approaches that refine or complement speculative design methods such as adversarial design [22], critiques of critical design [2], or futures studies [97], we view infrastructural speculations as useful for specific purposes and instances. They are not prescriptive. Instead, they are meant to aid design researchers interrogating the complex and ongoing entanglements among technologies, institutions, practices, and systems of power.

\section{Revealing Messiness Beyond Binaries}

Infrastructural speculations orient design researchers' explicit attention to the lifeworlds that operate implicitly in the background of speculative designs. The design tactics in this paper draw attention to lifeworlds in different ways such as articulating possible lifeworlds, looking at multiple practices and relationships that exist in a lifeworld, broadening the time horizons that are considered, or drawing attention to forms of power that exist in a lifeworld. We find that these tactics help designer researchers "stay with the trouble," [88] considering multiplicity and power when doing speculative design. In particular, they help explore the complex middle ground between three supposed binaries: dystopia/utopia, working/broken, and future/past.

\section{Dystopia/Utopia $\rightarrow$ Differences in the Everyday Mundane}

There can be a tendency to think about either utopian futures or some perfect future state (particularly in corporate futuring), or dystopian futures of control wielded with malevolent intent. However, these "hyperbolic narratives muddle the banality of more probable outcomes" [107:1368]. People encounter technologies in the mundanity of everyday life and new technologies get adopted and appropriated by and into existing institutions and systems of power. Moreover, dystopic speculations have been critiqued for hiding questions of race, class, and gender; and for pushing those concerns into an imagined future, not recognizing how 
people in the present already experience injustice and suffering [75].

Rather than erasing differences, infrastructural speculations draw attention to differences and the imaginaries, institutions, and power structures that support and enforce them. Together, the design tactics here begin to articulate and view lifeworlds from different subject positions and material conditions. They interrogate how technical artifacts become enrolled in existing communities of practice, legal and regulatory structures, economic agendas, and bureaucratic organizations. While all technical artifacts are imbued with politics [101], they are not solely beneficial or harmful on their own. Benefits and harms are co-constructed with the sociotechnical systems that artifacts get adopted into. Infrastructural speculations help design researchers explore the complexities in the uneven distributions of benefits and harms related to technologies, rather than through the universalizing lenses of utopia or dystopia.

Working/Broken $\rightarrow$ Ongoing Relations and Practices Infrastructures are never universally working or broken on their own; rather infrastructures may work for some but not for others, and artful labor and work is required to make an infrastructure function at a local level [15]. Infrastructural speculations bring this lens to thinking about visions of the future, complicating stories of working and broken technologies. The tactics presented in this paper draw attention to the relations and practices surrounding technical artifacts: How might a technical artifact work partially for some, but not for others? What practices and relationships might be necessary for a system to function, such as maintenance, repair, regulation, and management roles? What seams exist between new and past technologies, laws, and social norms? How might people bridge those seams?

\section{Future/Past $\rightarrow$ Whose Futures and Whose Imaginaries}

These tactics also help researchers interrogate how technical systems are enrolled in creating and supporting sociotechnical imaginaries. Infrastructures can be used as markers to indicate who is seen as being "in the future" (such as those with access to high speed internet and many digital technologies) compared to those who are seen as being "in the past" (those without the same amount of access). Following calls by critical and feminist scholars to reflect on who creates future worlds, and from what subject positions they craft visions of the future $[39,88]$, these tactics also bring attention to thinking about the potential implications or harms that can be done by valuing certain practices and populations as "ahead", and de-valuing practices and populations deemed as "behind" [84]. Whose futures get to matter, and who decides what is in the future and what is in the past? In particular, design tactics engaging historical imaginaries attempt to bring technologies and practices associated with the past to the center when thinking about futures, as a way to try to imagine alternative futures.

\section{Using Infrastructural Speculations}

The tactics described here provide an entry point into thinking beyond initial moments of invention and design, opening up to a broader set of stakeholders, practices, institutions, and related systems for speculative inquiry. This follows a call by Irani and Silberman to move from critical design to critical infrastructures [43], recognizing the labor involved in repair, maintenance, and communication also provide ways to generate and articulate new values and politics. As designers increasingly use modes of speculation to interrogate questions of broad, societal concern - such as climate change, the role of big tech in political radicalization, and widening income inequalities - there is a need to adapt the speculative design toolbox to include design and analytical approaches that explicitly focus on the broad and disparate impacts of infrastructures, as well as the maintenance and repair labor required to sustain and keep them working.

\section{CONCLUSION}

While speculative designs imply a lifeworld surrounding a speculative artifact, infrastructural speculations re-focus design researchers' explicit attention to the careful crafting and analysis of the lifeworld itself. Drawing on concepts of infrastructures - including a focus on practices and relationships; multiplicity of uses and experiences; and the longstanding power that infrastructural systems have to classify, sort, and affect human experiences - the design tactics presented in this paper offer a variety of strategies for re-focusing attention on the lifeworlds that tend to operate in the "background" of speculative design. These tactics help design researchers interrogate the complex and ongoing entanglements among technologies, institutions, practices, and systems of power when gauging the stakes of alternate lifeworlds. Infrastructural speculations are of pertinent importance as designers increasingly use modes of speculation to interrogate questions of broad societal concern, beyond moments of immediate invention and design, and beyond moments of individuals' use.

\section{ACKNOWLEDGEMENTS}

We thank our anonymous reviewers for their invaluable comments, as well as members of the 2019 Berkeley I School Doctoral Research \& Theory Workshop. This work was made possible in part by the support of NSF grants \#1752814 and \#190832, as well as the UC Berkeley Center for Long Term Cybersecurity (CLTC). Any opinions, findings, conclusions or recommendations expressed in this material are those of the authors and do not necessarily reflect the views of the NSF and CLTC.

\section{REFERENCES}

[1] James Auger. 2013. Speculative design: crafting the speculation. Digital Creativity 24, 1: 11-35. https://doi.org/10.1080/14626268.2013.767276

[2] Jeffrey Bardzell and Shaowen Bardzell. 2013. What is "critical" about critical design? In Proceedings of the SIGCHI Conference on Human Factors in Computing 
Systems - CHI '13, 3297. https://doi.org/10.1145/2470654.2466451

[3] Cynthia L. Bennett, Burren Peil, and Daniela K. Rosner. 2019. Biographical Prototypes: Reimagining Recognition and Disability in Design. In Proceedings of the 2019 on Designing Interactive Systems Conference - DIS '19, 35-47. https://doi.org/10.1145/3322276.3322376

[4] Peter L. Berger and Thomas Luckmann. 1991. The social construction of reality: A treatise in the sociology of knowledge. Penguin UK.

[5] Julian Bleecker. 2009. Design Fiction: A Short Essay on Design, Science, Fact and Fiction. Retrieved from http://www.nearfuturelaboratory.com/2009/03/17/desi gn-fiction-a-short-essay-on-design-science-fact-andfiction/

[6] Eli Blevis. 2018. Seeing What Is and What Can Be: On sustainability, respect for work, and design for respect. In Proceedings of the 2018 CHI Conference on Human Factors in Computing Systems - CHI '18, 1-14. https://doi.org/10.1145/3173574.3173944

[7] Mark Blythe. 2014. Research through design fiction: Narrative in Real and Imaginary Abstracts. In Proceedings of the SIGCHI Conference on Human Factors in Computing Systems (CHI '14), 703-712. https://doi.org/10.1145/2556288.2557098

[8] Geoffrey C. Bowker. 1994. Information mythology: The world of/as information. In Information Acumen. The Understanding and Use of Knowledge in Modern Business, Lisa Bud-Frierman (ed.). Routledge, 231247.

[9] Geoffrey C. Bowker, Karen Baker, Florence Millerand, and David Ribes. 2010. Toward Information Infrastructure Studies: Ways of Knowing in a Networked Environment. In International Handbook of Internet Research. Springer Netherlands, Dordrecht, 97-117. https://doi.org/10.1007/978-14020-9789-8_5

[10] Geoffrey C Bowker and Susan Leigh Star. 2000. Sorting things out: Classification and its consequences. MIT press.

[11] Pam Briggs, Patrick Olivier, Mark Blythe, John Vines, Stephen Lindsay, Paul Dunphy, James Nicholson, David Green, Jim Kitson, and Andrew Monk. 2012. Invisible design: Exploring Insights and Ideas through Ambiguous Film Scenarios. In Proceedings of the Designing Interactive Systems Conference on - DIS '12, 534. https://doi.org/10.1145/2317956.2318036

[12] Gregor Broll and Steve Benford. 2005. Seamful Design for Location-Based Mobile Games. In Lecture Notes in Computer Science (including subseries Lecture Notes in Artificial Intelligence and Lecture
Notes in Bioinformatics). 155-166. https://doi.org/10.1007/11558651_16

[13] Barry Brown, Julian Bleecker, Marco D'Adamo, Pedro Ferreira, Joakim Formo, Mareike Glöss, Maria Holm, Kristina Höök, Eva-Carin Banka Johnson, Emil Kaburuan, Anna Karlsson, Elsa Kosmack-Vaara, Jarmo Laaksolahti, Airi Lampinen, Lucian Leahu, Vincent Lewandowski, Donald McMillan, Anders Mellbratt, Johanna Mercurio, Cristian Norlin, Nicolas Nova, Stefania Pizza, Asreen Rostami, Mårten Sundquist, Konrad Tollmar, Vasiliki Tsaknaki, Jinyi Wang, Charles Windlin, and Mikael Ydholm. 2016. The IKEA Catalogue: Design Fiction in Academic and Industrial Collaborations. In Proceedings of the 19th International Conference on Supporting Group Work (GROUP '16), 335-344. https://doi.org/10.1145/2957276.2957298

[14] H. Claire Brown. 2018. How an algorithm kicks small businesses out of the food stamps program on dubious fraud charges. The Intercept. Retrieved September 19, 2019 from https://theintercept.com/2018/10/08/foodstamps-snap-program-usda/

[15] Jenna Burrell. 2018. Thinking relationally about digital inequality in rural regions of the U.S. First Monday 23, 6. https://doi.org/10.5210/fm.v23i6.8376

[16] Ashley Carse and David Kneas. 2019. Unbuilt and Unfinished. Environment and Society 10, 1: 9-28. https://doi.org/10.3167/ares.2019.100102

[17] Matthew Chalmers. 2003. Seamful design and ubicomp infrastructure. Proc. Ubicomp 2003 Workshop At The Crossroads: The Interacton of HCI and Systems Issues in Ubicomp.: 4.

[18] Paul Coulton, Joseph Lindley, Miriam Sturdee, and Michael Stead. 2017. Design Fiction as World Building. Proceedings of the 3nd Biennial Research Through Design Conference, March: 1-16. https://doi.org/10.6084/m9.figshare.4746964.Image

[19] Audrey Desjardins, Cayla Key, Heidi R. Biggs, and Kelsey Aschenbeck. 2019. Bespoke Booklets: A Method for Situated Co-Speculation. In Proceedings of the 2019 on Designing Interactive Systems Conference - DIS '19, 697-709. https://doi.org/10.1145/3322276.3322311

[20] Kristin Dew and David Ribes. 2019. Syllabus for HCDE300A: Foundations of Human-Centered Design $\&$ Engineering, University of Washington (Winter 2019).

[21] Kristin Dew and David Ribes. 2019. "Technofossils", Assignment description for HCDE300A: Foundations of Human-Centered Design \& Engineering, University of Washington (Winter 2019).

[22] Carl DiSalvo. 2012. Design and Agonism. In Adversarial Design. The MIT Press, Cambridge, 
Massachusetts.

[23] Paul Dourish and Genevieve Bell. 2011. Divining a Digital Future: Mess and Mythology in Ubiquitous Computing. The MIT Press, Cambridge, Massachusetts.

[24] Nora Draper. 2017. Fail Fast: The Value of Studying Unsuccessful Technology Companies. Media Industries Journal 4, 1: 1-19. https://doi.org/10.3998/mij.15031809.0004.101

[25] Anthony Dunne. 2005. Para-functionality: The Aesthetics of Use. In Hertzian Tales: Electronic Products, Aesthetic Experience, and Critical Design (2nd ed.). The MIT Press, Cambridge, Massachusetts, 43-68.

[26] Anthony Dunne and Fiona Raby. 2001. Design Noir: The Secret Life of Electronic Objects. Birkhauser.

[27] Anthony Dunne and Fiona Raby. 2013. Speculative Everything. The MIT Press, Cambridge, Massachusetts.

[28] Arturo Escobar. 2018. Introduction. In Designs for the Pluriverse: Radical Interdependence, Autonomy, and the Making of Worlds. Duke University Press, Durham. https://doi.org/10.1215/9780822371816

[29] Virginia Eubanks. 2015. Automating Inequality: How high-tech tools profile, police, and punish the poor. St. Martin's Press, New York.

[30] Laura Forlano. 2015. Critical Loop. Retrieved December 19, 2019 from https://id.iit.edu/projects/critical-loop/

[31] Nick Foster. 2013. The Future Mundane. Core77. Retrieved September 18, 2019 from https://www.core77.com/posts/25678/The-FutureMundane

[32] Sarah E. Fox. 2018. Maintaining the Menstruating Body: Feminist Interventions on Care Resources (Dissertation). University of Washington.

[33] Sarah E. Fox, Kiley Sobel, and Daniela K. Rosner. 2019. Managerial Visions: stories of upgrading and maintaining the public restroom with IoT. In Proceedings of the 2019 CHI Conference on Human Factors in Computing Systems - CHI '19, 1-15. https://doi.org/10.1145/3290605.3300723

[34] Batya Friedman, Peter H. Kahn, and Alan Borning. 2008. Value Sensitive Design and Information Systems. In The Handbook of Information and Computer Ethics, Kenneth Einar Himma and Herman T. Tavani (eds.). John Wiley \& Sons, Inc., 69-101.

[35] Bill Gaver and Heather Martin. 2000. Alternatives: exploring information appliances through conceptual design proposals. Proceedings of the SIGCHI conference on Human Factors in Computing Systems (CHI '00): 209-216. https://doi.org/10.1145/332040.332433

[36] R. Stuart Geiger and David Ribes. 2010. The work of sustaining order in wikipedia. Proceedings of the 2010 ACM conference on Computer supported cooperative work - CSCW'10: 117-126. https://doi.org/10.1145/1718918.1718941

[37] Nelson Goodman. 1978. Ways of Worldmaking. Hackett Publishing.

[38] Lars Hallnäs and Johan Redström. 2002. From use to presence: on the expressions and aesthetics of everyday computational things. ACM Transactions on Computer-Human Interaction 9, 2: 106-124. https://doi.org/10.1145/513665.513668

[39] Donna Haraway. 2016. Staying with the Trouble: Making Kin in the Chthulucene. Duke University Press, Durham.

[40] Lara Houston, Steven J Jackson, Daniela K Rosner, Syed Ishtiaque Ahmed, Meg Young, and Laewoo Kang. 2016. Values in Repair. In Proceedings of the 2016 CHI Conference on Human Factors in Computing Systems - CHI '16, 1403-1414. https://doi.org/10.1145/2858036.2858470

[41] Edmund Husserl. 1970. The crisis of European sciences and transcendental phenomenology: an introduction to phenomenological philosophy. Northwestern University Press, Evanston.

[42] Sarah Inman and David Ribes. 2019. "Beautiful Seams": Strategic Revelations and Concealments. In Proceedings of the 2019 CHI Conference on Human Factors in Computing Systems - CHI '19, 1-14. https://doi.org/10.1145/3290605.3300508

[43] Lilly Irani and M. Six Silberman. 2014. From critical design to critical infrastructure. Interactions 21, 4 : 32-35. https://doi.org/10.1145/2627392

[44] Steven J. Jackson, Paul N Edwards, Geoffrey C. Bowker, and Cory P. Knobel. 2007. Understanding infrastructure: History, heuristics and cyberinfrastructure policy. First Monday 12, 6: 1-8. https://doi.org/10.5210/fm.v12i6.1904

[45] Steven J. Jackson and Laewoo Kang. 2014. Breakdown, obsolescence and reuse. Proceedings of the 32nd annual ACM conference on Human factors in computing systems - CHI '14: 449-458. https://doi.org/10.1145/2556288.2557332

[46] Sheila Jasanoff. 2015. Future Imperfect: Science, Technology, and the Imaginations of Modernity. In Dreamscapes of modernity: Sociotechnical imaginaries and the fabrication of power (, Sheila Jasanoff and Sang-Hyun Kim (eds.). 1-47. Retrieved from http://iglp.law.harvard.edu/wpcontent/uploads/2014/10/Jasanoff-Ch-1.pdf

[47] Kat Jungnickel. 2015. Sewing as a design method. interactions 22, 6: 72-75. 
https://doi.org/10.1145/2834881

[48] Vera Khovanskaya, Eric P. S. Baumer, and Phoebe Sengers. 2015. Double Binds and Double Blinds: Evaluation Tactics in Critically Oriented HCI. In The Fifth Decennial Aarhus Conference on Critical Alternatives (AA '15), 12. https://doi.org/10.7146/aahcc.v1i1.21266

[49] David Kirby. 2010. The Future is Now: Diegetic Prototypes and the Role of Popular Films in Generating Real-world Technological Development. Social Studies of Science 40, 1: 41-70. https://doi.org/10.1177/0306312709338325

[50] Travis Kriplean, Ivan Beschastnikh, and David W. McDonald. 2008. Articulations of wikiwork. In Proceedings of the ACM 2008 conference on Computer supported cooperative work - CSCW '08, 47. https://doi.org/10.1145/1460563.1460573

[51] Joseph Lindley. 2016. A Pragmatics Framework for Design Fiction. In 11th EAD Conference Proceedings: The Value of Design Research. https://doi.org/10.7190/ead/2015/69

[52] Joseph Lindley and Paul Coulton. 2015. Back to the Future: 10 Years of Design Fiction. In Proceedings of the 2015 British HCI Conference (British HCI '15), 210-211. https://doi.org/10.1145/2783446.2783592

[53] Joseph Lindley and Paul Coulton. 2015. Game of Drones. In Proceedings of the 2015 Annual Symposium on Computer-Human Interaction in Play CHI PLAY'15, 613-618. https://doi.org/10.1145/2793107.2810300

[54] Joseph Lindley, Paul Coulton, and Miriam Sturdee. 2017. Implications for Adoption. In Proceedings of the 2017 CHI Conference on Human Factors in Computing Systems (CHI '17), 265-277. https://doi.org/10.1145/3025453.3025742

[55] Silvia Lindtner and Seyram Avle. 2017. Tinkering with Governance: Technopolitics and the Economization of Citizenship. Proceedings of the ACM on Human-Computer Interaction 1, CSCW: 118. https://doi.org/10.1145/3134705

[56] Conor Linehan, Ben J. Kirman, Stuart Reeves, Mark A. Blythe, Joshua G. Tanenbaum, Audrey Desjardins, and Ron Wakkary. 2014. Alternate endings: using fiction to explore design futures. In $\mathrm{CHI}$ '14 Extended Abstracts on Human Factors in Computing Systems (CHI EA '14), 45-48. https://doi.org/10.1145/2559206.2560472

[57] Kenneth Lipartito. 2003. Picturephone and the Information Age: The Social Meaning of Failure. Technology and Culture 44, 1: 50-81.

[58] Michael Lynch. 2012. Science and Technology Studies: Critical Concepts in the Social Science. Routledge.
[59] Matt Malpass. 2016. Critical Design Practice: Theoretical Perspectives and Methods of Engagement. The Design Journal 19, 3: 473-489. https://doi.org/10.1080/14606925.2016.1161943

[60] Ramia Mazé. 2019. Politics of Designing Visions of the Future. Journal of Futures Studies 23, 3: 23-38. https://doi.org/10.6531/JFS.201903_23(3).0003

[61] Gregg Mitman, Marco Armiero, and Robert S. Emmett (eds.). 2018. Future Remains: A Cabinet of Curiosities for the Anthropocene. University of Chicago Press, Chicago.

[62] Thomas P. Moran and R. J. Anderson. 1990. The workaday world as a paradigm for CSCW design. In Proceedings of the 1990 ACM conference on Computer-supported cooperative work-CSCW' 90 , 381-393. https://doi.org/10.1145/99332.99369

[63] Lisa P. Nathan, Batya Friedman, Predrag Klasjna, Shaun K. Kane, and Jessica K. Miller. 2008. Envisioning systemic effects on persons and society throughout interactive system design. Proceedings of the 7th ACM Conference on Designing Interactive Systems (DIS '08): 1-10. https://doi.org/10.1145/1753846.1754003

[64] Lisa P. Nathan, Predrag V Klasnja, and Batya Friedman. 2007. Value Scenarios: A Technique for Envisioning Systemic Effects of New Technologies. In CHI '07 Extended Abstracts, 2585-2590.

[65] Nicolas Nova, Katherine Miyake, Walton Chiu, and Nancy Kwon. 2012. Curious rituals: Gestural interaction in the digital everyday. Retrieved from http://curiousrituals.wordpress.com

[66] Luiza Prado de O. Martins and Pedro J. S. Vieira de Oliveira. 2016. Breaking the cycle of Macondo: Design and decolonial futures. XRDS: Crossroads, The ACM Magazine for Students 22, 4: 28-32. https://doi.org/10.1145/2930880

[67] William Odom, Sumeet Anand, Doenja Oogjes, and Jo Shin. 2019. Diversifying the Domestic: A Design Inquiry into Collective and Mobile Living. In Proceedings of the 2019 on Designing Interactive Systems Conference - DIS '19, 1377-1390. https://doi.org/10.1145/3322276.3323687

[68] Pedro Oliveira and Luiza Prado de O. Martins. 2014. Cheat Sheet for a Non- (or Less-) Colonialist Speculative Design. Medium. Retrieved December 19, 2019 from https://medium.com/a-parede/cheat-sheetfor-a-non-or-less-colonialist-speculative-design$9 \mathrm{a} 6 \mathrm{~b} 4 \mathrm{ae} 3 \mathrm{c} 465$

[69] Lisa Parks and Nicole Starosielski (eds.). 2015. Signal Traffic: Critical Studies of Media Infrastructures. University of Illinois Press.

[70] James Pierce. 2019. Lamps, Curtains, Robots: 3 scenarios for the future of the smart home. In 
Proceedings of the 2019 on Creativity and Cognition C\&C '19, 423-424.

https://doi.org/10.1145/3325480.3329181

[71] James Pierce and Eric Paulos. 2014. Some variations on a counterfunctional digital camera. In Proceedings of the 2014 conference on Designing interactive systems (DIS '14), 131-140.

https://doi.org/10.1145/2598510.2602968

[72] James Pierce and Eric Paulos. 2014.

Counterfunctional things: exploring possibilities in designing digital limitations. In Proceedings of the 2014 conference on Designing interactive systems DIS '14, 375-384.

https://doi.org/10.1145/2598510.2598522

[73] James Pierce, Phoebe Sengers, Tad Hirsch, Tom Jenkins, William Gaver, and Carl DiSalvo. 2015. Expanding and Refining Design and Criticality in HCI. In Proceedings of the 33rd Annual ACM Conference on Human Factors in Computing Systems (CHI '15), 2083-2092. https://doi.org/10.1145/2702123.2702438

[74] Michael Power and Richard Laughlin. 1996. Habermas, law and accounting. Accounting, Organizations and Society 21, 5: 441-465. https://doi.org/10.1016/0361-3682(95)00036-4

[75] Luiza Prado de O. Martins and Pedro Oliveira. 2014. Questioning the "critical" in Speculative \& Critical Design. Medium. Retrieved July 7, 2017 from https://medium.com/a-parede/questioning-the-criticalin-speculative-critical-design-5a355cac2ca4

[76] Luiza Prado de O. Martins and Pedro Oliveira. 2015. Futuristic Gizmos, Conservative Ideals: On (Speculative) Anachronistic Design. Modes of Criticism I. Retrieved from $\mathrm{http}: / /$ modesofcriticism.org/futuristic-gizmosconservative-ideals/

[77] Paul Graham Raven. 2013. An Introduction to Infrastructure Fiction: Guest Post By Paul Graham Raven. Superflux Blog. Retrieved September 19, 2019 from http://superflux.in/index.php/introductioninfrastructure-fiction-guest-post-paul-graham-raven/\#

[78] Daniela K. Rosner and Morgan Ames. 2014. Designing for repair? Infrastructures and materialities of breakdown. In Proceedings of the 17th ACM conference on Computer supported cooperative work \& social computing - CSCW' $14,319-331$. https://doi.org/10.1145/2531602.2531692

[79] Daniela K. Rosner, Samantha Shorey, Brock R. Craft, and Helen Remick. 2018. Making Core Memory: Design inquiry into gendered legacies of engineering and craftwork. In Proceedings of the $2018 \mathrm{CHI}$ Conference on Human Factors in Computing Systems - CHI '18, 1-13. https://doi.org/10.1145/3173574.3174105
[80] Ziauddin Sardar. 1993. Colonizing the future: the 'other' dimension of futures studies. Futures 25, 2: 179-187. https://doi.org/10.1016/00163287(93)90163-N

[81] Jentery Sayers. 2016. Design without a future. interactions 23, 6: 74-76. https://doi.org/10.1145/2991893

[82] Alfred Schutz. 1962. Phenomenology and the Social Sciences. In Collected Papers I. Phaenomenologica (Collection Publiée Sous le Patronage des Centres d'Archives-Husserl), vol 11, Maurice Natanson (ed.). Springer, Dordrecht, 118-139. https://doi.org/10.1007/978-94-010-2851-6_5

[83] Alfred Schutz and Thomas Luckmann. 1973. The structures of the life-world. Northwestern University Press, Evanston.

[84] Phoebe Sengers. 2011. What I learned on Change Islands. interactions 18, 2: 40. https://doi.org/10.1145/1925820.1925830

[85] Samantha Shorey and Daniela K Rosner. 2019. A Voice of Process : Re-Presencing the Gendered Labor of Apollo Innovation. communication +1 7, 2: 1-30. https://doi.org/10.7275/yen8-qn18

[86] Jonathan Silver and Paula Meth (eds.). 2019. Speculative infrastructures and cities in-the-making -A Workshop Magazine. Urban Geography and Urban Institute/SIID at the University of Sheffield. Retrieved from https://urbangeographyjournal.org/

[87] Robert Soden, Michael Skirpan, Casey Fiesler, Zahra Ashktorab, Eric P. S. Baumer, Mark Blythe, and Jasmine Jones. 2019. CHI4EVIL: Creative Speculation On the Negative Impacts of HCI Research. In Extended Abstracts of the 2019 CHI Conference on Human Factors in Computing Systems - CHI EA '19, 1-8. https://doi.org/10.1145/3290607.3299033

[88] Marie Louise Juul Søndergaard and Lone Koefoed Hansen. 2018. Intimate Futures: Staying with the Trouble of Digital Personal Assistants through Design Fiction. In Proceedings of the 2018 on Designing Interactive Systems Conference 2018 - DIS '18, 869880. https://doi.org/10.1145/3196709.3196766

[89] Susan Leigh Star and Karen Ruhleder. 1996. Steps Toward an Ecology of Infrastructure: Design and Access for Large Spaces Information. Information Systems Research 7, 1: 111-134.

[90] Nicole Starosielski. 2015. The Undersea Network. Duke University Press, Durham.

[91] Michael Stead. 2016. A Toaster For Life: Using Design Fiction To Facilitate Discussion On The Creation Of A Sustainable Internet of Things. DRS2016: Future-Focused Thinking 8: 1-20. https://doi.org/10.21606/drs.2016.455 
[92] Stephanie B Steinhardt. 2016. Breaking Down While Building Up: Design and Decline in Emerging Infrastructures. In Proceedings of the $2016 \mathrm{CHI}$ Conference on Human Factors in Computing Systems - CHI '16, 2198-2208. https://doi.org/10.1145/2858036.2858420

[93] Stephanie B Steinhardt and Steven J Jackson. 2015. Anticipation Work : Cultivating Vision in Collective Practice. In Computer Supported Cooperative Work and Social Computing, 443-453.

[94] Theresa Jean Tanenbaum, Karen Tanenbaum, and Ron Wakkary. 2012. Steampunk as design fiction. In Proceedings of the SIGCHI Conference on Human Factors in Computing Systems (CHI '12), 1583. https://doi.org/10.1145/2207676.2208279

[95] Cameron Tonkinwise. 2014. How We Intend to Future: Review of Anthony Dunne and Fiona Raby, Speculative Everything: Design, Fiction, and Social Dreaming. Design Philosophy Papers 12, 2: 169-187. https://doi.org/10.2752/144871314X14159818597676

[96] Janet Vertesi, David Ribes, Laura Forlano, Yanni Loukissas, and Marisa Leavitt Cohn. 2016. Engaging, Designing and Making Digital Systems. In The handbook of science and technology studies (6th ed.), Ulrike Felt, Rayvon Fouche, Clark A. Miller and Laurel Smith-Doerr (eds.). The MIT Press.

[97] Joost M. Vervoort, Roy Bendor, Aisling Kelliher, Oscar Strik, and Ariella E.R. Helfgott. 2015. Scenarios and the art of worldmaking. Futures 74 : 62-70. https://doi.org/10.1016/j.futures.2015.08.009

[98] Pedro J.S. Vieira de Oliveira and Luiza Prado de O. Martins. 2019. Designer/Shapeshifter: A Decolonizing Redirection for Speculative and Critical Design. In Tricky Design: The Ethics of Things, Tom Fisher and Lorraine Gamman (eds.). Bloomsbury Visual Arts, London, 103-114.

[99] Susann Wagenknecht and Matthias Korn. 2016. Hacking as Transgressive Infrastructuring: Mobile Phone Networks and the German Chaos Computer Club. In Proceedings of the 19th ACM Conference on Computer-Supported Cooperative Work \& Social Computing - CSCW'16, 1102-1115. https://doi.org/10.1145/2818048.2820027
[100]Mark Weiser. 1991. The Computer for the 21st century. Scientific American 265, 94-104.

[101]Langdon Winner. 1980. Do Artifacts Have Politics? Daedalus 109, 1: 121-136.

[102]Richmond Wong. 2019. Ethics Strikebreaking: Reflecting on Values \& Ethics in Design Practice with Design Fiction. In CHI 2019 Workshop on "CHI4Evil." Retrieved from https://www.dropbox.com/s/smt3ru625fuvyj2/CHI4E vil - Wong\%2C Ethics Strikebreaking - 2019-04-16 final.pdf? $\mathrm{dl}=0$

[103]Richmond Y. Wong and Steven J. Jackson. 2015. Wireless Visions: Infrastructure, Imagination, and U.S. Spectrum Policy. In Proceedings of the 18th ACM Conference on Computer Supported Cooperative Work \& Social Computing (CSCW'15). https://doi.org/10.1145/2675133.2675229

[104]Richmond Y. Wong and Vera Khovanskaya. 2018. Speculative Design in HCI: From Corporate Imaginations to Critical Orientations. In $\mathrm{New}$ Directions in 3rd Wave HCI, Michael Filimowicz (ed.). Springer, 175-202. https://doi.org/10.1007/9783-319-73374-6_10

[105]Richmond Y. Wong and Deirdre K. Mulligan. 2016. When a Product Is Still Fictional: Anticipating and Speculating Futures through Concept Videos. In Proceedings of the 2016 ACM Conference on Designing Interactive Systems (DIS '16), 121-133. https://doi.org/10.1145/2901790.2901801

[106]Richmond Y. Wong, Ellen Van Wyk, and James Pierce. 2017. Real - Fictional Entanglements: Using Science Fiction and Design Fiction to Interrogate Sensing Technologies. In Proceedings of the 2017 ACM Conference on Designing Interactive Systems (DIS '17). https://doi.org/10.1145/3064663.3064682

[107]Richmond Y Wong, Nick Merrill, and John Chuang. 2018. When BCIs have APIs: Design Fictions of Everyday Brain-Computer Interface Adoption. In Proceedings of the 2018 on Designing Interactive Systems Conference 2018 - DIS '18, 1359-1371. https://doi.org/10.1145/3196709.3196746 